\title{
Part defects identification in selective laser melting via digital image processing of powder bed anomalies
}

\author{
A. Boschetto ${ }^{1} \cdot$ L. Bottini ${ }^{1} \cdot$ S. Vatanparast ${ }^{1} \mathbb{D} \cdot$ F. Veniali $^{1}$
}

Received: 7 December 2021 / Accepted: 31 January 2022 / Published online: 22 February 2022

(c) The Author(s) 2022

\begin{abstract}
Despite the potential of additive manufacturing and specifically of selective laser melting, several considerable barriers exist to widespread utilization, especially in specific industries that produce high-value components. Quality control and mechanical characterization remain the most expensive challenge. The quality and mechanical properties of the manufactured parts are influenced by potential defects; the characteristics of these defects, such as size, shape, location, and distribution, have shown to play key roles in mechanical properties. This work proposes a methodology for providing the identification of powder bed anomalies and consequent part defects through a synchronized analysis of the powder layers via digital image processing. This method can be used to study the critical defects formation during the layerwise process, providing important information about their location without the use of expensive or destructive measurements.
\end{abstract}

Keywords Selective laser melting $\cdot$ Digital image processing $\cdot$ Defect detection $\cdot$ Powder bed $\cdot$ In situ monitoring

\section{Introduction}

Additive manufacturing (AM) plays an important role in direct manufacturing of parts characterized by complicated shapes. Metal AM is best suited for small to medium volume production of highly designed or specialized products [1]. It is well suited for complex parts that are designed to be lightweight through topology optimization, reducing part cycle time, cost, material waste, and energy consumption, all with added flexibility in the design of manufactured parts for the highest performance [2]. Among the various AM approaches, the Selective Laser Melting (SLM) process is one of the most used in the industry, which allows fabricating complex geometries with high material efficiency. It has been successfully used by high-precision industries in various fields [3]. However, lack of quality assurance is a technological barrier to high-value applications where component failure cannot be tolerated [4,5] and the required quality cannot be achieved using only an open-loop process [6]. Therefore, to increase the understanding of the high

S. Vatanparast

somayeh.vatanparast@uniroma1.it

1 Department of Mechanical and Aerospace Engineering, Via Eudossiana 18, 00184 Rome, Italy complexity of physical phenomena and the mechanisms of defect formation during manufacturing, reliable defect detection and characterization are required [7, 8]. The SLM process involves complex physical processes, such as absorption and transfer of laser energy, rapid melting, and solidification of the material, microstructure development, flow in a molten bath, and material evaporation [9]. As a result of these variables, the process is characterized by defects such as porosities, incomplete melt holes, fractures, and impurities, among others [10]. These defects affect the mechanical and physical properties of a manufactured part and limit the applicability of SLM [11, 12]. Monitoring the powder bed anomalies and their propagation across layers plays a fundamental role in better understanding the final part defects signature. Most of the commonly used methods such as metrological approaches for surface characterization have proven to be unsuitable for determining important features such as undercuts and sub-surfaces pores; other methods need to be used to study the surface and volumetric defects typical of additively manufactured materials [12-15]. 


\subsection{In-situ monitoring related work}

In-situ monitoring of metal AM processes is a key issue to determine the quality and stability of the process during the layer-wise production of the part. The quantities that can be measured via in-situ sensing can be referred to as "process signatures" and can represent the source of information to detect possible defects [16] and have become major research in literature $[4,17-20]$ for the AM community. These signatures on the final part can be categorized in two classes: first, observable signatures which can be indicated and measured during the process by using in-situ devices; second is derived signatures which can be determined through analytical models or simulation [21]. In-process monitoring technologies, specifically imagedbase methods, have primarily focused on monitoring melt pool [22-25], plume and spatters signatures [18, 26-28]. However, the quality of parts produced by SLM is determined not only by the fusion bond between successive powder layers and hatches, but also by the integrity of the powder bed and the stability of the powder distribution [29]. Irregularities and discontinuities in the powder bed [30], unfavorably affect the physical interaction between the laser beam and the material, resulting in inconsistent processing and, in some cases, porosity [31]. Therefore, the signature of powder bed is one of the most important factors that play a great role in part quality and should be studied for a better understanding of the defects.

The granular nature of the powder bed and the shiny surface of the scanned areas are critical problems for image acquisition. Many studies [19, 32-35] paid efforts on developing optimum powder bed lighting and adequate imaging systems. In [36, 37] authors investigated the possibility to employ a thresholding technique for detecting superelevated edges automatically. In [38], the authors employed picture stacks taken under various brightness circumstances to extract features and analyze existing abnormalities. The categorization, however, was based on local knowledge, which may not be enough for classifying anomalies. In fact, it is not clear how anomalies on a single layer can affect the final part quality and interactions between layers should be studied from a broader point of view.

In this study, a digital image processing (DIP) approach to investigate part quality produced by SLM has been presented, which relates powder bed anomalies to the final part quality. The DIP is a rapid and cost-effective tool for characterizing powder bed errors. The unique method used for this study is easy to use and, by processing thousands of images from the powder bed, it gives access to different types of anomalies across the entire powder bed. Information about the size and location of the defects are provided to reduce the number of post-production non-destructive tests, which are expensive and not so accurate for large parts. The proposed method employs the machine built-in CCD camera without additional modification. The analysis detects anomalies directly related to the final part defects.

\subsection{Powder bed defects}

Defects on final parts can be observed even in the case that optimal process parameters, appropriate and verified scanning and build-up strategies are set [39]. The source of these defects can be of several types. They can be caused by process induced issues, e.g., the powder properties variability, leading to porosity, balling, cracking, oxide inclusions [40]. The part geometry and its alignment, the support structures and their location on the build plate can provide unfavorable fabrication conditions. Miscalibration or damaged equipment, such as a worn blade, can create anomalies [31, 41]. Various studies investigated the types and classification of defects on common alloys [12, 18-20, 42]. Many of the critical defects, as well as the overall reliability and stability of the SLM build process, are directly related to the powder application process [43]. However, according to [28, 42], in most of the cases, the anomalies induced by the powder handling and spreading system are not the real cause of defects, but the consequence of powder bed impurities such as spatter [30], excessive edges [30, 41] protruding from the thin powder layer [44]. Consequently, the interaction between the recoater and these anomalies in the powder bed leads to discontinuities in the layer and severely affects the stability of the process [40]. In these conditions, uneven powder layers alter the physical interaction of the laser beam with the material, and lead to uneven processing and porosity (gas porosity or lack of fusion) [45]. Due to the motion of the recoating system, anomalies created in one area of the powder layer may move along the recoating direction. Moreover, anomalies created in one layer can propagate through the next layer and create anomalies that spread across multiple layers and impact the quality of the final part.

\section{Material and methods}

The material used in this study is the AlSi $10 \mathrm{Mg}$. It is a critical raw material in SLM for its low density and particle's shape. Low density limits the protecting gas velocity, therefore lowering the capability to clean the laser sputtering. In the case of aluminum alloy creating spherical powder particles is hard. A lack of sphericity may influence the powder spreading process and lead to more local bed defects. Laser melting critically depends on the ability of the powder spreading system for delivering a thin powder 
layer, which is complicated since aluminum powders are light with poor flowability, particularly in the presence of moisture. These issues induce the formation of heaps when spreading the powder, which results in an uneven thickness of the powder layers [46].

In Fig. 1a the SEM characterization of the used powder is reported. Deviation from spherical shape and agglomerations can be observed. The distribution is slightly irregular (Fig. 1b) with D50 parameter, which indicates the point of the distribution below which the $50 \%$ of the material is contained, at $28.9 \mu \mathrm{m}$. D10 and D90 are $12.2 \mu \mathrm{m}$ and $40.7 \mu \mathrm{m}$ respectively, leading to a span of $89 \%$.

An EOSINT ${ }^{\circledR}$ M290 SLM machine was used to test the procedure. It is equipped with a $400 \mathrm{~W}$ Ytterbium fiber continuum laser with a beam spot size of $100 \mu \mathrm{m}$ and a building platform of $250 \times 250 \times 325 \mathrm{~mm}^{3}$. Prior to starting the construction, the machine was calibrated according to the documented supplier procedure. Gas atomized AlSi10Mg powders provided by EOS GmbH were employed. Table 1 shows the composition of used powders.

The process parameters were established according to the EOS standard ones for this material: $370 \mathrm{~W}$ laser power, $30 \mu \mathrm{m}$ layer thickness, $1300 \mathrm{~mm} / \mathrm{s}$ scan speed, $190 \mu \mathrm{m}$ hatch distance, $200{ }^{\circ} \mathrm{C}$ building platform temperature. The strategy used for scanning was the stripe type with a stripe length and a stripe length overlap of $7 \mathrm{~mm}$ and $0.02 \mathrm{~mm}$, respectively. To guarantee a high final density and to reduce residual stresses the stripes were rotated by $67^{\circ}$ with respect to the previous layer.

To prepare the necessary data for the procedure, the following steps were taken. Virtual models were created using standard solid modeling tools, such as SolidWorks, and incorporated into Wolfram Mathematica, using a mathematical formulation. Through EOS RPTools, STL files prepared through Materialize Magic were confirmed using laser path simulation. The final pre-processing step was provided in EOS PRINT, where the models and their supports were oriented and positioned with respect to the recoater and shielding gas.

The detachment from the building platform was provided by an automatic abrasive metallographic cutting. In order to avoid additional defects, particular care was paid to the selection of processing parameters: for the purpose, a $\mathrm{SiC}$ abrasive wheel $400 \mathrm{~mm}$ in diameter was employed at $40 \mathrm{~m} / \mathrm{s}$ cutting speed and $20 \mathrm{~mm} / \mathrm{min}$ feed speed with the use of water emulsion lubricant. The proposed methodology was demonstrated by defect detection via destructive and nondestructive traditional methods. Metallurgical cuts were provided by a manual Struers Labotom- 5 equipment. Sections were grinded, polished, and etched with Weck's reagent. The images were observed using a Leica DM 5000 optical image microscope. SLMed parts were analyzed by means of morphological maps. A Mitutoyo Surftest SJ-412 equipped with an additional micro-controlled axes wasemployed. The stylus was $180 \mathrm{~mm}$ in length allowing $2.4 \mathrm{~mm}$ vertical height.

\subsection{Image calibration and enhancement procedure}

The EOSINT ${ }^{\circledR}$ M290 is originally equipped with a CCD video camera 1280 pixels $\times 1024$ pixels resolution (Fig. $2 b$ ). Since the F-theta lens, must be positioned orthogonally with respect to the platform leaving no space for the auxiliary vision system, (Fig. 2a), the optical path of the camera cannot be orthogonal to the platform consequently images are distorted with both a perspective and radial deformations.

The video camera position angle, $\theta$, is $13.8^{\circ}$ which affects the possible direct measuring across the images. During the process, images of the powder bed are taken in two different categories: the former, called "after recoating" (AR), is acquired after the recoater spread a fine layer of powder; the latter, namely the "after exposure" (AE), is achieved at the end of the laser processing.
Fig. 1 SEM photo of the used AlSi10Mg powder (a) and equivalent diameter particle and cumulative distributions (b)
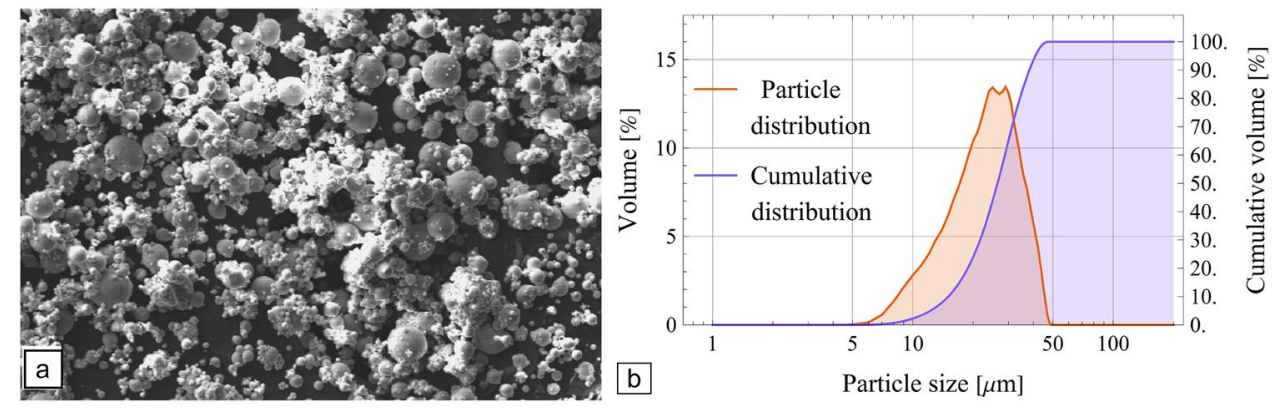

\begin{tabular}{lllllllllll}
\hline $\mathrm{Si}$ & $\mathrm{Fe}$ & $\mathrm{Cu}$ & $\mathrm{Mn}$ & $\mathrm{Mg}$ & $\mathrm{Ni}$ & $\mathrm{Zn}$ & $\mathrm{Pb}$ & $\mathrm{Sn}$ & $\mathrm{Ti}$ & $\mathrm{Al}$ \\
\hline $9-11$ & $\leq 0.55$ & $\leq 0.05$ & $\leq 0.45$ & $0.20-0.45$ & $\leq 0.05$ & $\leq 0.10$ & $\leq 0.05$ & $\leq 0.05$ & $\leq 0.15$ & $\mathrm{Bal}$ \\
\hline
\end{tabular}

Table 1 Chemical composition (wt $\%$ ) of the AlSi10Mg powders 
Fig. 2 Schematic of the camera position (a) and frontal view of the real system (b)

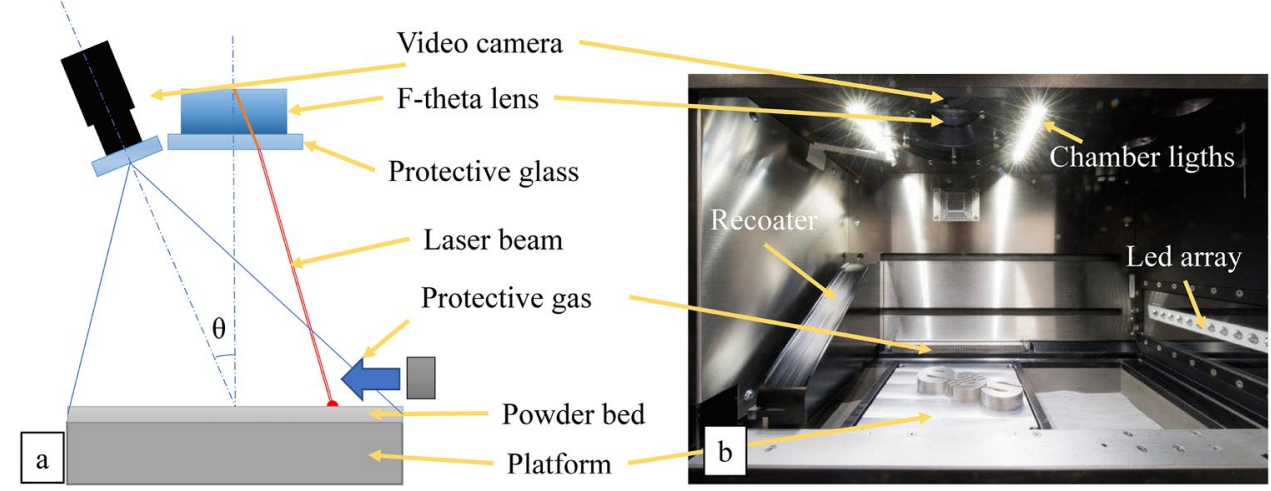

As mentioned earlier, the image distortion makes it necessary to perform a calibration. The pinhole model is the most frequent one which is based on the principle of collinearity, where each point in the object space is projected by a straight line through the projection center into the image plane. Equation (1) defines projection for pinhole model where $u, v$ and $x, y, z$ are the image and real coordinates, and $\mathrm{M}$ is the geometric transformation which consists of a translation and a rotation.

$\left[\begin{array}{l}u \\ v \\ 1\end{array}\right]=M\left[\begin{array}{l}x \\ y \\ z \\ 1\end{array}\right]$

Although the pinhole model can express the projection relationship, the most common correction is for radial lens distortion, which is approximated by polynomial functions.

Equation (2) defines polynomial function where $k_{1}, k_{2}$ are the coefficients of radial distortion and $r_{i}$ the radial distance.

$\left[\begin{array}{l}\delta u_{i}^{(r)} \\ \delta v_{i}^{(r)}\end{array}\right]=\left[\begin{array}{c}\tilde{u}_{i}\left(k_{1} r_{i}^{2}+k_{2} r_{i}^{4}+\ldots\right) \\ \tilde{v_{i}}\left(k_{1} r_{i}^{2}+k_{2} r_{i}^{4}+\ldots\right)\end{array}\right]$

Unfortunately, because the centers of the lens curvatures are not exactly collinear, this is insufficient to compensate for distortion. The so-called decentering distortion is added to consider radial and tangential components as defined by Eq. (3):

$\left[\begin{array}{l}\delta u_{i}^{(t)} \\ \delta v_{i}^{(t)}\end{array}\right]=\left[\begin{array}{c}2 p_{1} \tilde{u}_{i}+p_{2}\left(r_{i}^{2}+2 \tilde{u}_{i}^{2}\right) \\ p_{1}\left(r_{i}^{2}+2 v_{i}^{2}\right)+2 p_{2} \tilde{u}_{i} \tilde{v}_{i}\end{array}\right]$

where $p_{1}$ and $p_{2}$ are experimentally determined coefficients.

The combination of the pinhole model with the radial distortion correction can provide the entire set of parameters, effectively defining the transformation.

This problem is clearly nonlinear, and the Levenberg-Marquardt optimization method has been shown to provide fast convergence. However, incorrect initialization may result in unsuccessful calibration. To find the commencement and then proceed with the optimization method, a direct linear transformation is suggested.

The most common solution is to use known targets. A grid pattern was placed onto the platform and used for this purpose in this article. The same pattern is used to provide the machine's laser calibration procedure: it is a photo printed grid, and the known geometry was used to input many calibration points.

A design for the purpose code was developed in Wolfram Mathematica 12 platform. The code aimed at determining the linear transformation that yielded the initial rotation and translation coefficients. To find the general transformation, a Levenberg-Marquardt nonlinear fitting was used. The undeformed image was cropped to the building area, and local image enhancement was used to improve contrast and brightness. The entire routine was applied to all the jobs images and saved with appropriate naming that included the job, the layer position, and the type (AE or AR).

\subsection{Digital image processing}

Each AR image underwent two types of analysis. The first step is the $2 \mathrm{D}$ analysis, which is used to detect defects in the powder bed development process. The second approach allows for the identification of anomalies based on their volume for understanding their potential impact.

Because of the granular behavior of the powder bed, there is a lot of noise in the images. As a consequence, the analysis is characterized by multistep data processing. To find the background, the image is filtered using a 3D Gaussian function [47]. Image subtraction is used to separate the foreground from the background, and noise is greatly reduced. In this action, attention is paid to distinguishing between noise caused by the light scattering of a properly developed bed and minor flaws. The image is segmented using morphological binarization, which uses hysteresis thresholding to convert the multichannel image into an image where each pixel has a value of 0 or 1 . The discovered region is superimposed 
on the original to highlight the damaged area. This allows selecting an area that is enhanced and denoised by using a more computationally intensive method. The Perona-Malik $[48,49]$ filtering makes use of anisotropic diffusion which may preserve sharp edges and fine details. This method, which is commonly used in medical imaging, allows for the cleaning of the background and the creation of uniformity within the defect.

Although the $2 \mathrm{D}$ analysis can provide valuable information on the powder bed, it does not consider the interactions between layers namely the propagation across surrounding layers. To overcome these limitations the anomalies are analyzed by means of their volume. A benefit of this approach is that small anomalies, i.e., entities one or a few layers thick revealed in $2 \mathrm{D}$ analysis, are not considered. For the purpose the data are structured in a multilevel array, the so-called 3D image format commonly used in computer tomography and other medical images.

The procedure is applied to AR images to have the powder bed anomalies over the entire working volume, and to $\mathrm{AE}$ images to determine the scanned area. The last goal was obtained by removing anomalies lying inside and outside the part by using 3D erosion and 3D dilation operators. By multiplying $\mathrm{AR}$ and $\mathrm{AE} 3 \mathrm{D}$ images, i.e., each pixel is the product of the corresponding pixels in the input images, the AR anomalies outside the part are eliminated. The output is a 3D representation of $A R$ anomalies inside the part. This information indicates where a real defect on the fabricated part can potentially occur.

\section{Results and discussion}

\subsection{Calibration results}

The calibration procedure enables the generation of undeformed images that can be directly measured by defects and their location in the object space. The photo of the original known grid pattern is shown in Fig. 3a. It was positioned on the platform, allowing for selecting 2601 points. Direct linear fitting enabled was used to make the nonlinear fitting converge. To reduce computing time, the resulting interpolation was approximated. The warping matrix is defined by:

$M=\left(\begin{array}{ccc}0.990181 & -0.077353 & 0.086987 \\ -0.008297 & 0.881207 & -9.871239 \\ -0.000012 & -0.000173 & 1 .\end{array}\right)$

Figure $3 b$ depicts a vector field plot representation of warping. the transformation is significantly nonlinear and asymmetric. The calibrated image, as shown in Fig. 3c, is
Fig. 3 Original IM (a), transformation displacement (b), calibrated IM (c) distribution of the deviation between cross center points (d)
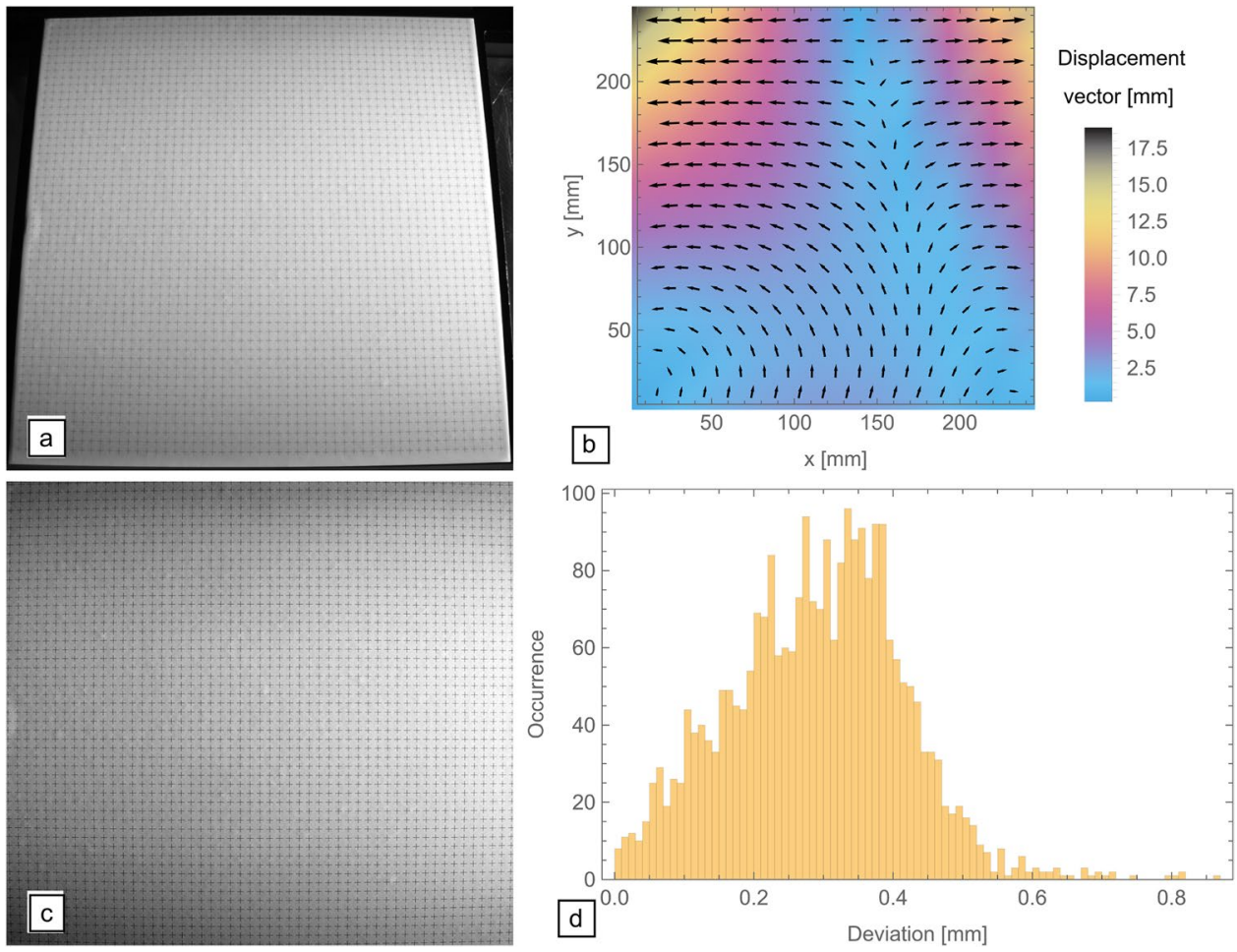

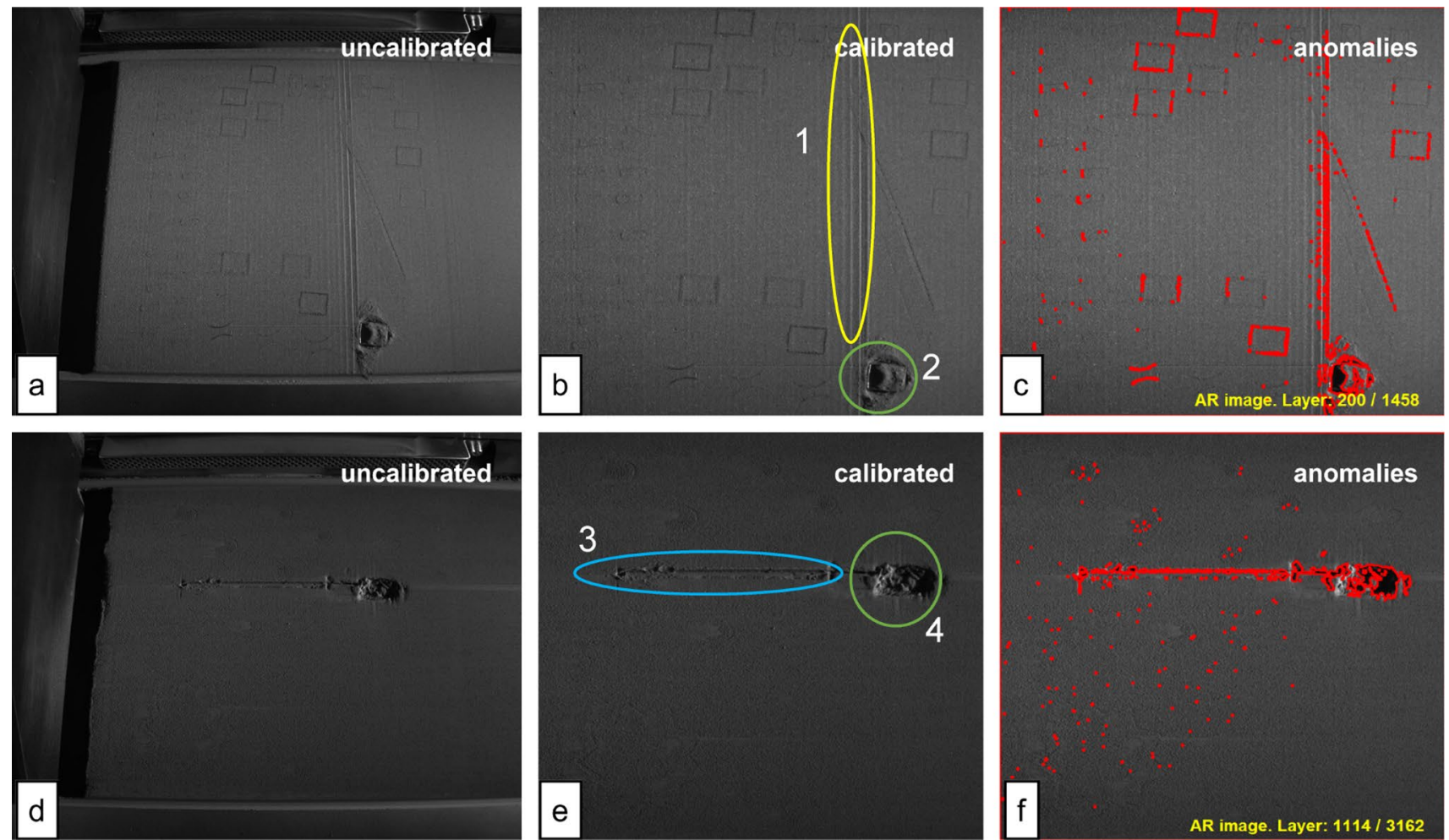

Fig. 4 Powder bed defect detection, a job 1 original image, $\mathbf{b}$ calibrated image with defects, recoater vibration (zone 1), part elevation (zone 2), $\mathbf{c}$ highlighted defects via DIP, $\mathbf{d}$ job 2 original image, e cali-

free of the previous perspective and radial distortions. The histogram describes the analysis of residuals, i.e., the differences between known and measured positions (Fig. 3d). More than $90 \%$ of the points lie less than $0.34 \mathrm{~mm}$ away from the target. The image scale is $0.3125 \mathrm{~mm} /$ pixel.

\subsection{Feature segmentation in 2D}

A job consisting of several parts was considered for the 2D analysis. Figure 4 shows the outputs related to two layers. In Fig. 4a, the original image highlights a marked distortion which may markedly affect the measurement of the potential location of the defects on the build plate. After the calibration, the outcoming image is reported in Fig. $4 \mathrm{~b}$. At this layer, two areas with major defects can be observed: vertical lines (zone 1 in Fig. 4b) could be due to recoater vibrations that typically occur when the blade strikes a previously scanned area lying just below the powder layer [43]. This is typically caused by a failed support structure or a bad building orientation in relation to the recoater [50]. It is demonstrated that powder layer quality is sensitive to the underlying substrate [51]; super-elevated edges can interact with the recoater, resulting in vertical markings, namely the recoater hopping [52]. A possible cause of this vibration could be caused by other defects present in this layer, brated image with defects, particle dragging (zone3), support destruction (zone 4), f defect detection via DIP

namely zone 2 , where a large lack of recoating is detected. Figure $4 \mathrm{c}$ depicts the processing of an AR image. After the background removal, the morphological binarization, and the edge detection, the borders of these areas are easy to identify. The impact of detected anomalies can be expected on surface roughness, geometry inaccuracy, and metallurgical defects depending upon whether the effects occur over the surface of the part or inside it.

The second layer which requires attention is the 1114th, as shown in Fig. 4d. Also, in this case, a line and a big defect can be noticed. The horizontal one (zone 3 in Fig. 4e) typically occurs when a recoating mechanism is damaged [4] or severe wear of the blade edge occurs [53]. These stripes can be caused by the dragging of a relatively large contaminant (zone 4 in Fig. 4e) across the powder bed, e.g., support structures torn by the blade [54]. These defects are correctly detected (Fig. 4f).

\subsection{Defect propagation across layers}

Anomalies formed in one layer could propagate through the next layer and cause different types of defects including microstructure, surface defects and geometry deformation. When considering a single layer, an anomaly can disappear after one or a few layers if the recoater can cover it. In this 

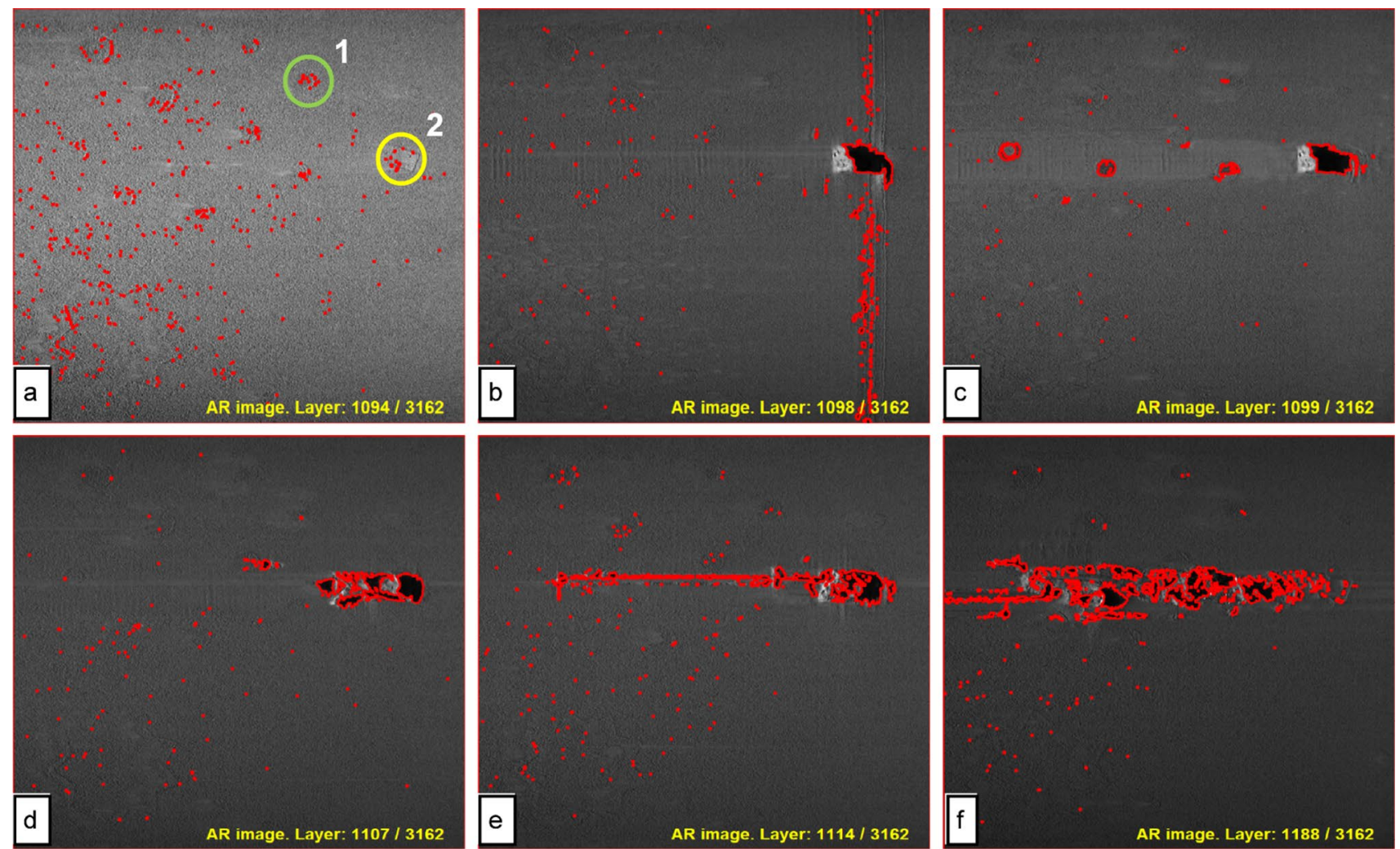

Fig. 5 Defect propagation and detection across subsequent layers on powder bed, anomalies detection on powder bed (a) vibration defects induced due to zone 2 anomaly (b), big lack of powder on the pow-

case, the defect caused by the anomaly is limited or negligible. Conversely, if the recoater is not able to recover the powder bed error, the anomaly can spread across many layers and lead to serious defects on final part. In Fig. 5a two examples of this phenomenon are shown in the shown layer (1094th), there are many areas characterized by small anomalies. Zones 1 and 2 are apparently of the same type. The former is completely absorbed by the recoater in the next layer, and it totally disappears at layer 1098th. Conversely, the latter is increasing its intensity and at the same layer it is so strong that a vibration is induced (Fig. 5b). Also, it can be assumed that the big anomalies and the vibrations feed one another up to this layer. At the layer 1099 shown in Fig. 5c, the vibrations ceased, but the defect is too big to be covered by the spreading system. Here another type of propagation occurs: many holes are now generated in the recoater direction (Fig. 5d), and after 7 layers, some elements are dragged for $180 \mathrm{~mm}$ (Fig. 5e). The situation is not recovered and becomes catastrophic at layer 1188th as shown in Fig. 5 f. This propagation plays an important role in the final part, but it is difficult to evaluate the magnitude across layers only by $2 \mathrm{D}$ analysis. As mentioned in Sect. 2.2 the anomalies on a single layer are not directly related to the actual defect that will appear on the fabricated part. However, the uneven der bed (c), generation of more holes in recoater direction (d) dragged elements on powder bed (e), spread anomalies on powder bed (f)

powder bed, affects the interaction between the laser and the powder bed leading to internal or external defects. Thus, an integrated 3D analysis where the layers are merged into a unique structure is necessary. This way, the powder bed anomalies of the surrounding layers are aggregated, allowing easy identification of potential defects. At the same time, the small entities present in the powder bed are naturally eliminated if they are not a part of a propagated anomaly.

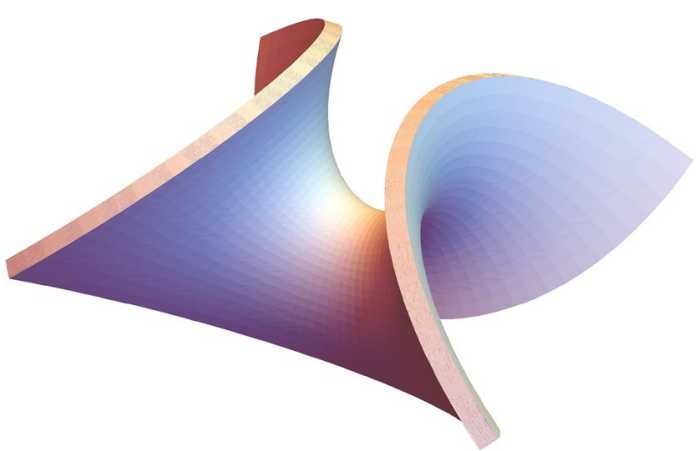

Fig. 6 Surface defects on Enneper surface printed via SLM 


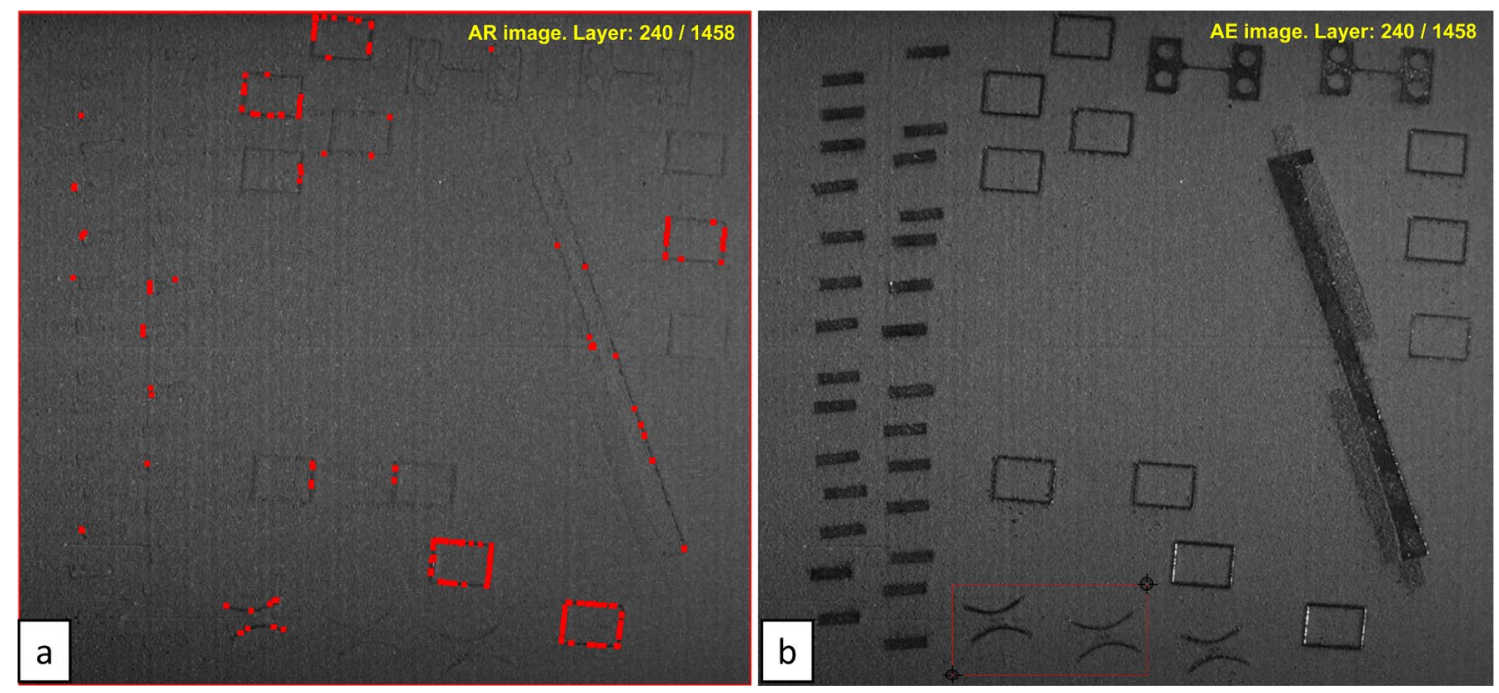

Fig. 7 AR image of build plate (a), selection of the region of interest (ROI) area (b)

\subsection{D analysis for surface defects detection}

A particular geometry was selected to prove the capability of the method. It is a 3D representation of the wellknown Enneper's minimal surface, namely a surface with zero mean curvature according to the Enneper Weierstass parametrization [55]. After providing a thickening of the surface in accordance with [56], the STL shown in Fig. 6 was generated.

Several components were fabricated in the same job to consider conditions characterized by mutual interactions between different parts of the same platform, typical of industrial production. Through the $2 \mathrm{D}$ analysis, the layers were investigated, and anomalies in the selected parts were highlighted. The layer 240 is shown in Fig. 7a, where three Enneper parts can be noticed in the bottom of the platform. A ROI is selected on AE images to focus on the first two Enneper parts and to reduce the computational time (Fig. 7b). It can be noticed that the platform is populated by many elements whose interactions can cause unpredictable effects on parts that are apparently well designed and positioned.

By rolling the various layers, the powder bed of the selected area is well recoated, as shown in Fig. 8a, where the Perona-Malik and Gaussian filter are applied. At layer 386 (Fig. 8b), the second Enneper is affected by an anomaly which may cause a defect on the final part. At the next layer, shown in Fig. 8c, the previous flaw is recovered whilst a bigger void is now present on the first Enneper.

This second anomaly persists for several layers: after 11 layers (Fig. 8d) are grown, after 21 layers (Fig. 8e) are reduced until layer 420 is completely absorbed by the recoating operation (Fig. 8f). This analysis highlights that these two anomalies are deeply different in volume. The height of the former is only one layer and can probably be neglected. The latter is characterized by a propagation across about 21 layers, leading to an anomaly height of about $0.6 \mathrm{~mm}$.

$3 \mathrm{D}$ analysis is a straightforward way of detecting anomalies inside the scanned area without manually understanding the propagation across layers. The previous Enneper parts were analyzed and compared. The filtered AR images were stacked into a 3D image, generating the result shown in Fig. 9a. The false colors highlight the different dimensions of the defects. This representation is interesting but confusing because many defects are positioned outside the scanned area. By applying the procedure for $\mathrm{AE}$ images where the powder bed defects are removed by 3D morphological operations, the scanned volume is reported in Fig. 9b. Since the powder bed lacks affect the laser consolidation, it is well evident that at around layer 400, the intensity of the color is different. By intersecting both the previous results, a 3D image of only the anomalies in the scanned area is obtained (Fig. 9c). The areas in the part affected by the anomalies are visible, and they have an extension in the stratification direction of $0.6 \mathrm{~mm}$. By simply looking at the manufactured part, it is difficult to notice any problem on the surface (Fig. 9d) but by analysing the surface by means of a profilometric measurement, a flaw is detected. In Fig. 9e the 3D map of the surface highlights a line parallel to the y axes, which is parallel to the platform. This bump has a variable elevation ranging between 150 and $250 \mu \mathrm{m}$ and a width of about $500 \mu \mathrm{m}$ which is in accordance with the previous considerations. Elsewhere the surface is characterized by the common SLM behavior with a maximum peak-to-valley height of about $150 \mu \mathrm{m}$ [57]. 

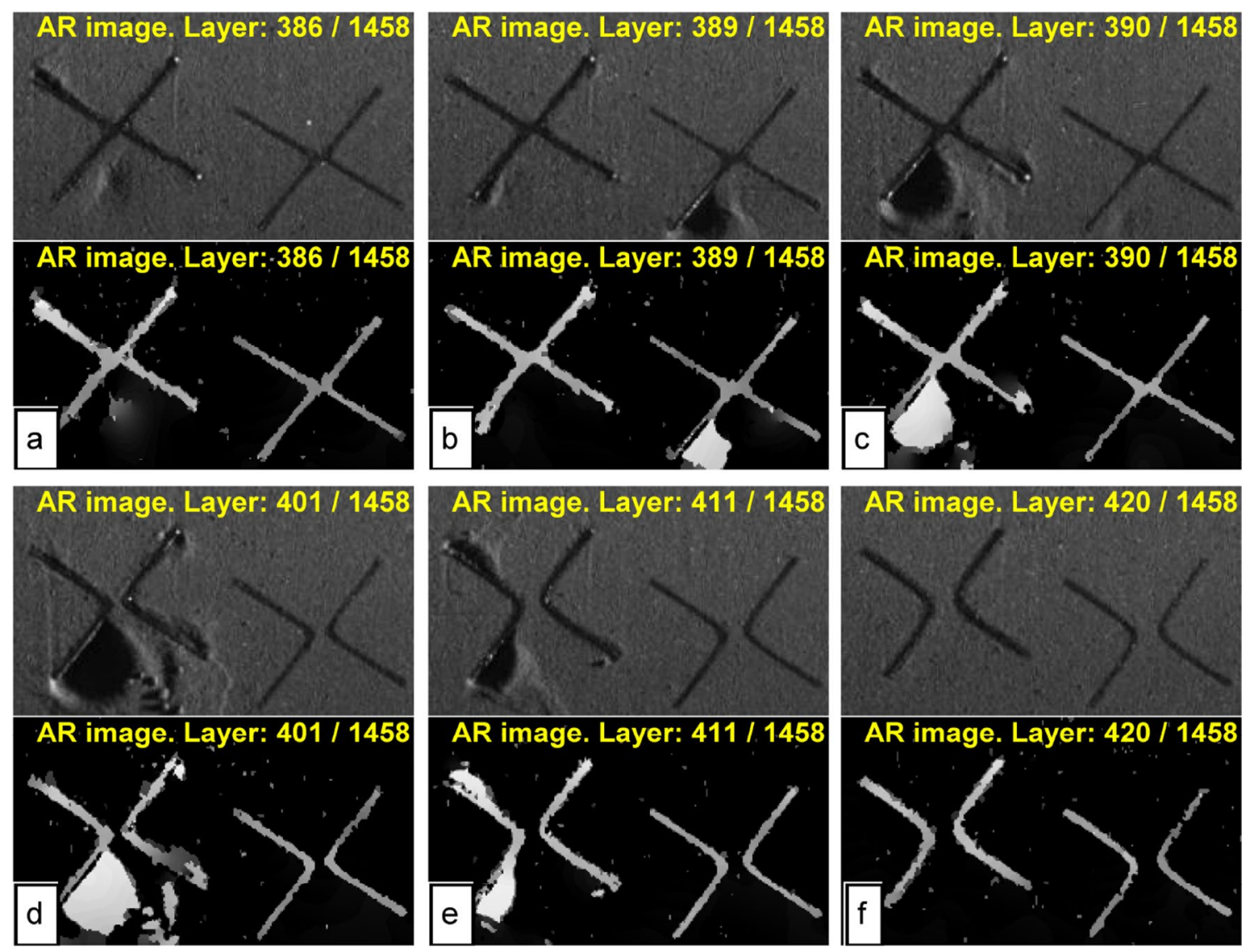

Fig. 8 ROI images of powder bed without flaws $(\mathbf{a}, \mathbf{f})$, damages on the first Enneper $(\mathbf{b})$, propagated anomalies across layers $(\mathbf{c}-\mathbf{e})$

The 3D analysis was applied to the second Enneper for comparison. The 3D image for the AR is heavily populated by anomalies: in Fig. 10a, many small defects can be noticed, and in the bottom part, linear aggregations reveal possible vibrations of the recoater. The latter anomalies lie outside the scanned area. In fact, intersecting with the 3D image of the AE, which shows a uniform colouring of the area (Fig. 10b), no particular defects are observed in the scanned area (Fig. 10c). By selecting the same measuring zone in this part (Fig. 10d), the result in Fig. 10e is obtained. It is well evident that no defect is present and only the usual SLM surface now characterizes the area $[58,59]$.

\subsection{D analysis for internal defects detection}

Uneven powder layers can interfere with the physical interaction between the laser beam and the material, resulting in uneven processing such as laser absorption, heat transfer, and consolidation. This will lead to metallurgical defects such as different types of porosity that are really difficult to detect without prompting. In order to study the effect of powder bed anomalies on the porosity, the inclined parallelogram, positioned at the first column fourth row in
Fig. 7b, was considered. It is relevant to notice that the component exposure strategy was modified to improve the surface quality: the adopted volumetric energy density caused local deformation of the scanned area, resulting in a lack of recoating, especially on the part contours (vertical and inclined and overhanging surfaces). Conversely, to the previous case, it is crucial to investigate the effect on the porosity caused by these issues above in the part under-skin. The $\mathrm{AE}$ 3D image is shown in Fig. 11a. This geometry is characterized by different slopes: $45^{\circ}$ and $-45^{\circ}$ for inclined surfaces, $90^{\circ}$ for vertical walls; and $0^{\circ}$ for horizontal faces. Overhanging surfaces, namely those at a $-45^{\circ}$, are supposed to have most of the defects as well as sharpened edges, which are subjected to residual stresses and deformations that may interact with the recoater. The powder bed around this component is densely characterized by anomalies, as pointed out by the 3D analysis reported in Fig. 11b. The defects on the part are mainly positioned on edges and overhanging surfaces (Fig. 11a).

The metallographic analysis of the transversely crosssectioned samples is reported in Fig. 12.

By sectioning the upper part of the specimen near the corner, as indicated by the arrow in Fig. 12a, an irregularly 


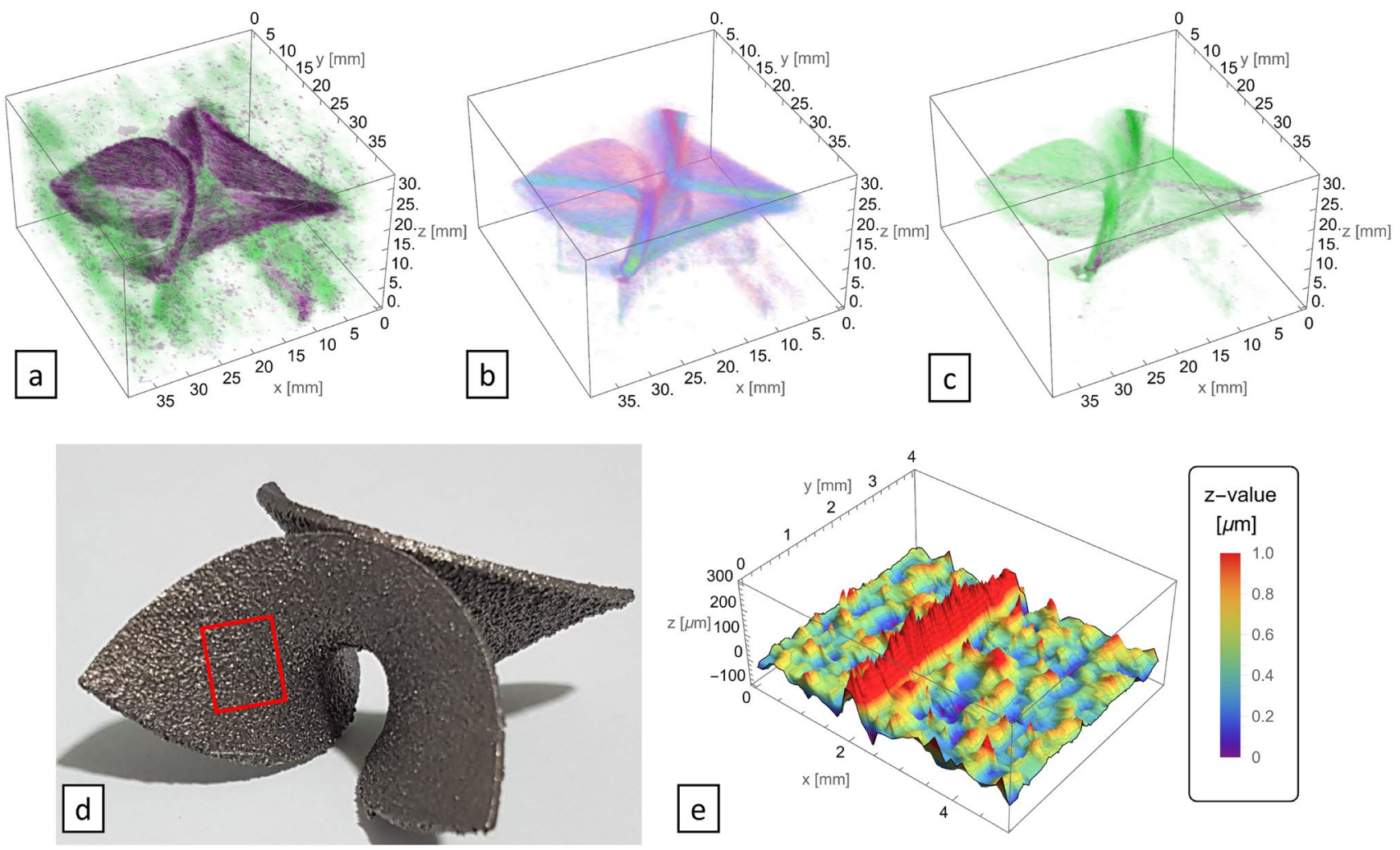

Fig. 9 3D images of the damaged Enneper, 3D images AR (a), 3D image AE (b), multiplication AR \& AE (c), printed part (d), 3D map of highlighted zone (e)

shaped pore, attributable to a lack of fusion [60], was found. It is positioned in an area which was scanned by contour strategy, as evidenced by the track. Inside, the common crystalline structure [61] of internal hatching can be noticed. It can be assumed that this defect is caused by uneven processing conditions which caused a porosity partially filled by powder which was not completely melted. Anomalies are suggested by analysis on the edge of the $45^{\circ}$ surface. Taking the section at the height indicated by the arrow (Fig. 12b), a bigger lack of fusion is present at the interface between the contour and infill areas. Conversely, the analysis of the horizontal top surface of the specimen does not claim any defects. This is confirmed by the observation of the etched images. An example is shown in Fig. 12c where neither the contour nor the hatched ones are affected by defects. When moving to the opposite corner the analysis reveals the presence of many anomalies in the powder bed. The metallographic cut proved that in this area some big defects are present: the one shown in Fig. 12d has a length of $180 \mu \mathrm{m}$. The overhanging surface, namely $-45^{\circ}$, is mainly affected by anomalies in the bed. The cut at the indicated height validated the 3D analysis: Fig. 12e shows a big oblong void $150 \mu \mathrm{m}$ in equivalent diameter.

\section{Conclusion}

Monitoring powder bed images obtained throughout the build process can offer precise information on the root of tiny to large flaws, allowing for a full analysis of defect distribution across the part. This information can subsequently be employed to enhance process parameters, design modifications, and possibly support structure, predict part functionality, and provide information about damaged tools like recoater blades.

The DIP technique presented in this work evaluates a large number of images collected during the process after recoating and after exposure by directly using the machine built-in camera. No modification of the system is thus required but a careful calibration was necessary to avoid radial and perspective distortion. The calibration accuracy resulting from the proposed procedure was of the same order as the pixel dimension. The developed methodology is divided in a 2D and 3D analyses: the former aims to automatically highlight the anomalies and the former considers the defects between layers which highly affect the generation of the final part defects. The selected examples demonstrated the ability of the methodology to automatically find anomalies in 2D, providing information about their source such as the recoater vibration and particle dragging. The use of the 

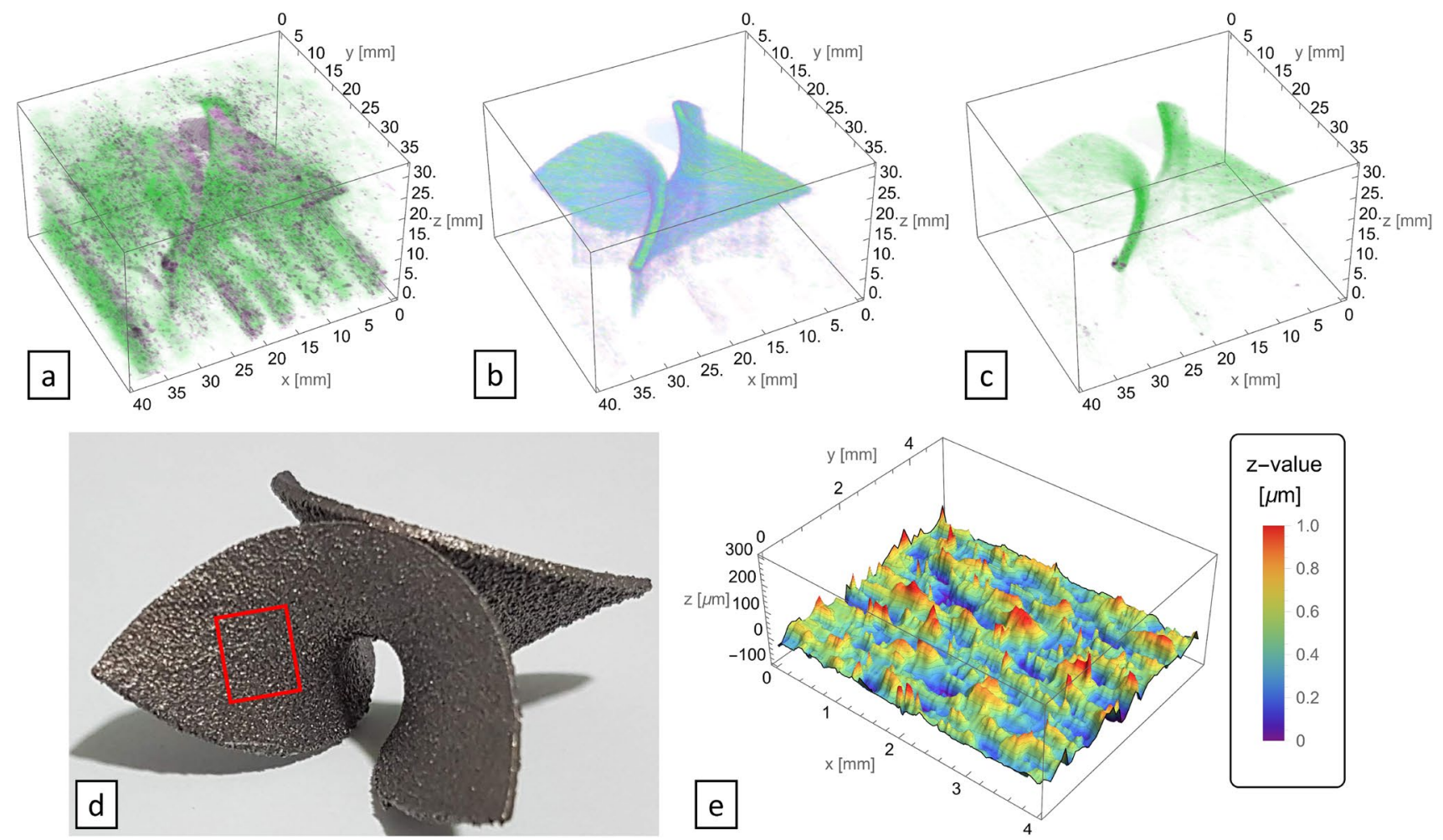

Fig. 10 3D image of the defect free Enneper,3D images AR (a), 3D images AE (b), multiplication AR \& AE (c), printed part (d), 3D map of highlighted zone (e)

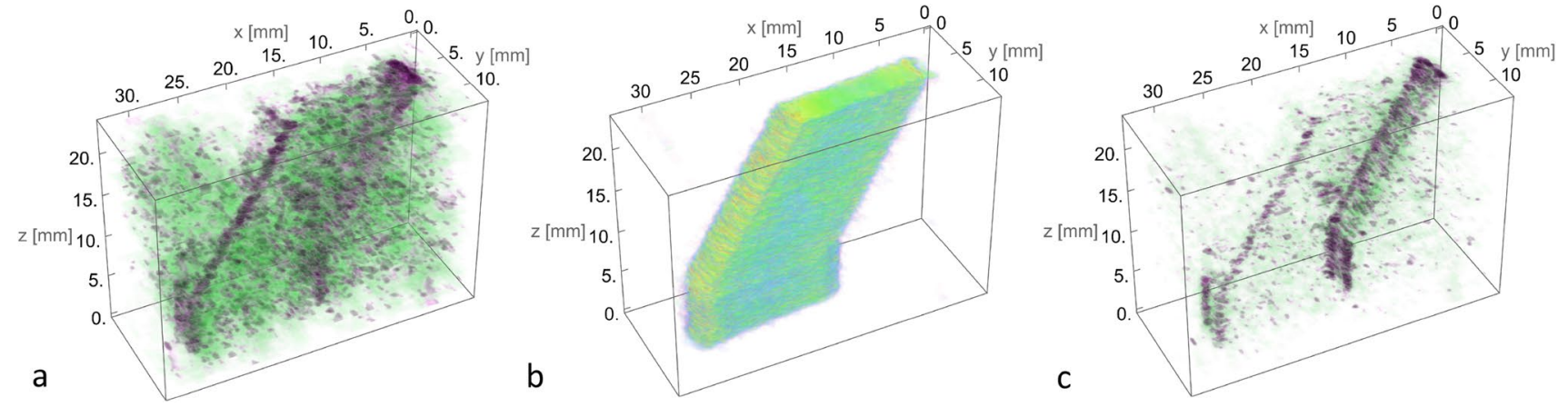

Fig. 11 3D Specimen (a), powder bed (b), and anomalies on part (c) 3D image

Perona-Malik filter allowed for the elimination of powder bed noise without losing anomaly edge quality. The results demonstrated the need to consider how the anomalies propagate across layers leading to negligible or consistent part defects. The 3D analysis can be directed to a single or more parts by selecting a specific ROI. This allows to generate an aggregated structure, namely a $3 \mathrm{D}$ image, that is easy to read with a reduced computing time. Some components were analyzed by traditional characterization systems and destructive methods to prove the capability of the methodology. $3 \mathrm{D}$ analysis carried out on two identical parts demonstrated that the method can predict the presence of surface flaws which that are hard to identify, whilst it can assure faultless surfaces where no anomalies are indicated. Moreover, internal defects are well recognized, and the suggested locations demonstrate the real presence of voids, whose shape 

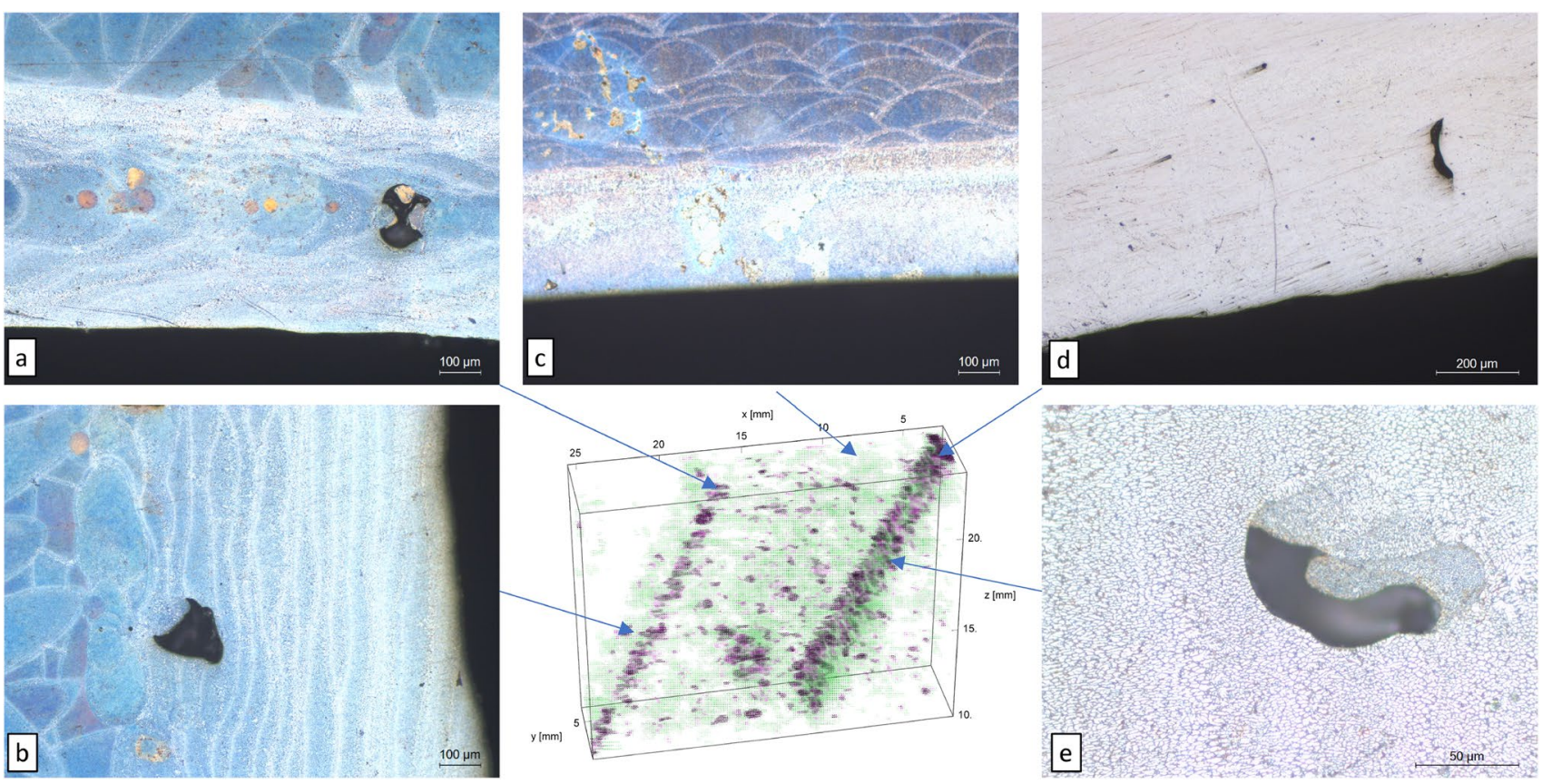

Fig. 12 Optical micrograph of build parts in cross section (a-e)

suggests processing problems in the spreading and/or in the consolidation.

The presented method gives a great opportunity to predict the occurrence of defects in a fast and easy way without restrictions. Further developments will concern the development of a trained system able to relate the shape and dimension of the anomalies to the final defect.

Availability of data and materials Authors confirm that the data and material supporting the findings of this work are available within the article.

Code availability Not applicable.Open Access This article is licensed under a Creative Commons Attribution 4.0 International License, which permits use, sharing, adaptation, distribution and reproduction in any medium or format, as long as you give appropriate credit to the original author(s) and the source, provide a link to the Creative Commons licence, and indicate if changes were made. The images or other third party material in this article are included in the article's Creative Commons licence, unless indicated otherwise in a credit line to the material. If material is not included in the article's Creative Commons licence and your intended use is not permitted by statutory regulation or exceeds the permitted use, you will need to obtain permission directly from the copyright holder. To view a copy of this licence, visit http://creativecommons.org/licenses/by/4.0/.

\section{References}

1. Gibson I, Rosen D, Stucker B, Khorasani M (2021) Additive manufacturing technologies. Springer, Berlin
2. Chua CK, Leong KF (2017) 3D printing and additive manufacturing: principles and applications. World Scientific Publishing Co Pte Ltd, Singapore

3. Wohlers T, Diegel O (2017) Wohlers Report 2017. Wohlers Associates Inc, Fort Collins

4. Everton S, Hirsch M, Stravroulakis P, Leach RK, Clare AT (2016) Review of in-situ process monitoring and in-situ metrology for metal additive manufacturing. J Mater Design 95:431-445

5. Zhang YS, Ye D, Fuh JYH, Zhu K (2020) Powder-bed fusion process monitoring by machine vision with hybrid convolutional neural networks. IEEE Trans Ind Inform 16:5769-5779. https:// doi.org/10.1109/TII.2019.2956078

6. Lott P, Schleifenbaum H, Meiners W, Wissenbach K, Hinke C, Bültmann J (2011) Design of an optical system for the in-situ process monitoring of selective laser melting (SLM). J Phys Proc 12:683-690. https://doi.org/10.1016/j.phpro.2011.03.085

7. Bourell D, Leu M, Rosen D (2017) Roadmap for additive manufacturing: identifying the future of freeform processing. Solid Free Fabr Proc

8. Tapia G, Elwany A (2014) A review on process monitoring and control in metal-based additive manufacturing. J Manuf Sci Eng. https://doi.org/10.1115/1.402854

9. Zhang B, Li Y, Bai Q (2017) Defect formation mechanisms in selective laser melting: a review. Chin J Mech Eng 30:515-527. https://doi.org/10.1007/s10033-017-0121-5

10. Gu D (2015) Laser additive manufacturing of high-performance materials. Springer, Berlin

11. Sanaei N, Fatemi A et al (2019) Defect characteristics and analysis of their variability in metal L-PBF additive manufacturing. $\mathbf{J}$ Mater Design. https://doi.org/10.1016/j.matdes.2019.108091

12. Aboulkhair NT, Simonelli M et al (2019) 3D printing of aluminum alloys: additive manufacturing of aluminum alloys using selective laser melting. J Prog Mater Sci. https://doi.org/10.1016/j.pmatsci. 2019.100578

13. Zerbst U, Hilgenberg $\mathrm{K}$ et al (2017) Damage development and damage tolerance of structures manufactured by selective laser 
melting—a review. J Proc Struct Integr 7:141-148. https://doi. org/10.1016/j.prostr.2017.11.071

14. HamidiNasab M et al (2019) Combined effect of surface anomalies and volumetric defects on fatigue assessment of AlSi7Mg fabricated via laser powder bed fusion. J Addit Manuf. https:// doi.org/10.1016/j.addma.2019.100918

15. Gong $\mathrm{H}$, Rafi $\mathrm{K}$ et al (2015) Influence of defects on mechanical properties of Ti-6Al-4 V components produced by selective laser melting and electron beam melting. J Mater Design 86:545-554. https://doi.org/10.1016/j.matdes.2015.07.147

16. Repossini G, Laguzza V et al (2017) On the use of spatter signature for in-situ monitoring of laser powder bed fusion. J Addit Manuf. https://doi.org/10.1016/j.addma.2017.05.004

17. Abdelrahman M, Reutzel EW et al (2017) Flaw detection in powder bed fusion using optical imaging. J Addit Manuf 15:1-11. https://doi.org/10.1016/j.addma.2017.02.001

18. Taheri H, Rashid B, Mohammad Shoaib M et al (2017) Powderbased additive manufacturing - a review of types of defects generation mechanisms detection. J Electr Comput Eng Publ 2:172-209 https://lib.dr.iastate.edu/ece_pubs/189

19. Grasso M, Colosimo BM (2017) Process defects and in-situ monitoring methods in powder bed fusion: a review. J Meas Sci Technol. https://doi.org/10.1088/1361-6501/aa5c4f

20. Malekipour E, El-Mounayri H (2018) Common defects and contributing parameters in powder bed fusion AM process and their classification for online monitoring and control: a review. J Adv Manuf Technol 95:527-550. https://doi.org/10.1007/ s00170-017-1172-6

21. Mani M, Lane B et al (2015) Measurement science needs for real-time control of additive manufacturing powder bed fusion processes. Natl Inst Stand Technol. https://doi.org/10.6028/NIST. IR.8036

22. Zhang Y, Soon Hong G et al (2018) Extraction and evaluation of melt pool, plume and spatter information for powder-bed fusion AM process monitoring. J Mater Design 156:458-469. https://doi. org/10.1016/j.matdes.2018.07.002

23. Goossens LR, Van Hooreweder B (2021) A virtual sensing approach for monitoring melt-pool dimensions using high speed coaxial imaging during laser powder bed fusion of metals. J Addit Manuf. https://doi.org/10.1016/j.addma.2021.101923

24. Spears TG, Gold SA (2016) In-process sensing in selective laser melting (SLM) additive manufacturing. Integr Mater Manuf Innov. https://doi.org/10.1186/s40192-016-0045-4

25. Gautam P (2020) Particle tracking of a simulated melt pool of selective laser melting. Montana Tech Library

26. Ye D, Ying HsiFuh J et al (2018) In situ monitoring of selective laser melting using plume and spatter signatures by deep belief networks. ISA Trans. https://doi.org/10.1016/j.isatra.2018.07.021

27. Yakout M, Phillips I et al (2020) In-situ monitoring and detection of spatter agglomeration and delamination during laser-based powder bed fusion of Invar 36. Opt Laser Technol. https://doi.org/ 10.1016/j.optlastec.2020.106741

28. Yang D, Li H et al (2020) In situ capture of spatter signature of SLM process using maximum entropy double threshold image processing method based on genetic algorithm. J Opt Laser Technol. https://doi.org/10.1016/j.optlastec.2020.106371

29. Xiao L, Lu M, Huang H (2020) Detection of powder bed defects in selective laser sintering using convolutional neural network. J Adv Manuf Technol 107:2485-2496. https://doi.org/10.1007/ s00170-020-05205-0

30. Gong H (2013) Generation and detection of defects in metallic parts fabricated by selective laser melting and electron beam melting and their effects on mechanical properties. J Electronic Theses and Dissertations. Paper 515. https://doi.org/10.18297/etd/515

31. Foster BK, Reutzel EW et al (2020) Optical, layerwise monitoring of powder bed fusion. Center for Innovative Material Processing through Direct Digital Deposition (CIMP-3D) Applied Research Laboratory, The Pennsylvania State University

32. Grasso M, Colosimo BM (2017) Process defects and in situ monitoring methods in metal powder bed fusion: a review. Meas Sci Technol 28:044005

33. Zhang B, Ziegert J et al (2016) In situ surface topography of laser powder bed fusion using fringe projection. J Addit Manuf 12:100-107

34. Li Z, Liu X et al (2018) In situ 3D monitoring of geometric signatures in the powder-bed-fusion additive manufacturing process via vision sensing methods. J Sens. https://doi.org/10.3390/s1804 1180

35. Tan Phuc L, Seita M et al (2019) A high-resolution and large fieldof-view scanner for in-line characterization of powder bed defects during additive manufacturing. J Mater Design. https://doi.org/10. 1016/j.matdes.2018.107562

36. Jacobsmuhlen JZ, Kleszczynski S et al (2014) Robustness analysis of imaging system for inspection of laser beam melting systems. In: Proceedings of the 2014 IEEE emerging technology and factory automation (ETFA), pp 1-4. https://doi.org/10.1109/ETFA. 2014.7005262

37. Jacobsmuhlen Z, Kleszczynski S et al (2013) High resolution imaging for inspection of laser beam melting systems. In: IEEE international instrumentation and measurement technology conference (I2MTC), pp 707-712. https://doi.org/10.1109/I2MTC. 2013.6555507

38. Gobert C, Reutzel EW et al (2018) Application of supervised machine learning for defect detection during metallic powder bed fusion additive manufacturing using high resolution imaging. J Addit Manuf 21:517-528. https://doi.org/10.1016/j. addma.2018.04.005

39. du Plessis A, Yadroitsava I, Yadroitsev I (2020) Effects of defects on mechanical properties in metal additive manufacturing: a review focusing on X-ray tomography insights. J Mater Design. https://doi.org/10.1016/j.matdes.2019.108385

40. Stugelmayer E. Characterization of process induced defects in laser powder bed fusion processed AlSi10Mg Alloy, Montana Tech Library, Graduate Theses \& Non-Theses, p 157

41. Deckers YE, Craeghs J et al (2009) Investigation on occurrence of elevated edges in selective laser melting. In: International solid freeform fabrication symposium, pp 673-85

42. Kim FH, Moylan SP (2018) Literature review of metal additive manufacturing defects. National Institute of Standards and Technology. https://doi.org/10.6028/NIST.AMS.100-16

43. Scime L, Beuth J (2018) A multi-scale convolutional neural network for autonomous anomaly detection and classification in a laser powder bed fusion additive manufacturing process. J Addit Manuf 24:273-286. https://doi.org/10.1016/j.addma. 2018.09.034

44. Kleszczynski S, zur Jacobsmühlen J et al (2012) Error detection in laser beam melting systems by high resolution imaging. Institute of Imaging and Computer Vision

45. Scime L, Siddel D, Baird S, Paquit V (2020) Layer-wise anomaly detection and classification for powder bed additive manufacturing processes: a machine-agnostic algorithm for real-time pixelwise semantic segmentation. J Addit Manuf. https://doi. org/10.1016/j.addma.2020.101453

46. Zhang J, Song B et al (2019) A review of selective laser melting of aluminum alloys: processing, microstructure, property and developing trends. J Mater Sci Technol 35:270-284. https://doi. org/10.1016/j.jmst.2018.09.004

47. Russ JC, Neal FB (2017) The image processing handbook. Taylor \& Francis Group, Routledge

48. Perona P, Malik J (1990) (1190) Scale-space and edge detection using anisotropic diffusion. IEEE Trans Pattern Anal Mach Intell 12:629-639 
49. Kamalaveni V, AnithaRajalakshmi R, Narayanankutty KA (2015) Image denoising using variations of Perona-Malik model with different edge stopping functions. J Proc Comput Sci 58:673-682. https://doi.org/10.1016/j.procs.2015.08.087

50. Yadroitsev I, Yadroitsava I, Du Plessis A (2021) Basics of laser powder bed fusion. In: Yadroitsev I, Yadroitsava I, Du Plessis A, MacDonald E (eds) Fundamentals of laser powder bed fusion of metals, additive manufacturing materials and technologies. Elsevier, Amsterdam, pp 15-38

51. Le TP, Wang X, Davidson KP, Fronda JE, Seita M (2021) Experimental analysis of powder layer quality as a function of feedstock and recoating strategies. Addit Manuf. https://doi.org/ 10.1016/j.addma.2021.101890

52. Leach R, Carmignato S (2020) Precision metal additive manufacturing.https://doi.org/10.1201/9780429436543

53. Craeghs T, Clijsters S, Yasa E, Kruth JP (2011) Onlizne quality control of selective laser melting. In: 22nd annual international solid freeform fabrication symposium - an additive manufacturing conference, SFF 2011

54. Kleszczynski S, Zur Jacobsmühlen J, Sehrt JT, Witt G (2012) Error detection in laser beam melting systems by high resolution imaging. In: 23rd annual international solid freeform fabrication symposium-an additive manufacturing conference, SFF 2012

55. Weierstrass K (1866) Über die Flächen deren mittlere Krümmung überall gleich null ist. Monatsber. Berliner Akad., 612-625

56. Bordoni M, Boschetto A (2012) Thickening of surfaces for direct additive manufacturing fabrication. J Rapid Prototyp 18:308-318
57. Boschetto A, Bottini L, Veniali F (2017) Roughness modeling of AlSi10Mg parts fabricated by selective laser melting. J Mater Process Technol 241:154-163

58. Leary M, Khorasani M, Sarker A, Tran J, Fox K, Downing D, Du Plessis A (2021) Surface roughness. In: Yadroitsev I, Yadroitsava I, Du Plessis A, MacDonald E (eds) Fundamentals of laser powder bed fusion of metals, additive manufacturing materials and technologies. Elsevier, Amsterdam, pp 179-213

59. Boschetto A, Bottini L, Macera L, Veniali F (2020) Post-processing of complex SLM parts by barrel finishing. Appl Sci. https:// doi.org/10.3390/app10041382

60. Du Plessis A (2021) Porosity in laser powder bed fusion. In: Yadroitsev I, Yadroitsava I, Du Plessis A, MacDonald E (eds) Fundamentals of laser powder bed fusion of metals, additive manufacturing materials and technologies. Elsevier, Amsterdam, pp 155-178

61. Trevisan F, Calignano F, Lorusso M, Pakkanen J, Aversa A, Ambrosio EP, Lombardi M, Fino P, Manfredi D (2017) On the selective laser melting (SLM) of the AlSi10Mg alloy: process, microstructure, and mechanical properties. Materials. https://doi. org/10.3390/ma10010076

Publisher's Note Springer Nature remains neutral with regard to jurisdictional claims in published maps and institutional affiliations. 